\title{
Affordability of Outer-Planet Exploration A Pragmatic Rationale for Implementing a Cold-Propulsion Based Energy-Efficient Spacecraft Infrastructure
}

Arturo R. Casillas (Jet Propulsion Laboratory, California Institute of Technology) (818) 393-2632 arturo.r.casillas@jpl.caltech.edu

with

Gregory Barnett (NASA Marshall Space Flight Center)

Carl Engelbrecht (Applied Physics Laboratory, Johns Hopkins University) Carl S. Guernsey (Jet Propulsion Laboratory, California Institute of Technology) James McKinnon (Frontier Aerospace Company)

Michael Preudhomme (Jet Propulsion Lab, California Institute of Technology) Jonathan R. Reh (Jet Propulsion Laboratory, California Institute of Technology)

Fred C. Wilson (Aerojet Rocketdyne Company)

endorsed by

Sushil Atreya (University of Michigan)

Patricia M. Beauchamp (Jet Propulsion Lab, California Institute of Technology) Anthony Freeman (Jet Propulsion Laboratory, California Institute of Technology) Mark Hofstadter (Jet Propulsion Laboratory, California Institute of Technology)

Rosaly Lopes (Jet Propulsion Laboratory, California Institute of Technology) William B. McKinnon (Washington University in St. Louis)

Kim R. Reh (Jet Propulsion Laboratory, California Institute of Technology)

\section{A White Paper Submitted to the Decadal Survey on Planetary Science and Astrobiology 2023-2032}

July 27,2020 


\section{Power Requirements Reduction Enables Mission Affordability}

In the last decadal survey (Vision and Voyages for Planetary Science in the Decade 2013-2022), the National Academy of Sciences (NAS) identified the key Solar System bodies to study in order to address the Priority Science Questions across three overarching Crosscutting Themes. One common denominator among most of the destinations identified - Comets, Asteroids, Trojans, Kuiper belt objects, Enceladus, Europa, Io, Ganymede, Jupiter, Saturn, Uranus, Titan, Mars, the Moon - is that the spacecraft needed to reach them can do so using more affordable solar power, as compared to nuclear power. Recent advances in solar array technology now make it possible to reach not only Saturn (aphelion $10.1 \mathrm{AU}$ ) using solar power, but even Uranus and its moons (aphelion 20.1 AU). However, the increased mass, complex deployment mechanisms and body dynamics management, associated with the large solar arrays required can still pose significant and costly engineering challenges. Clearly, any technology that can further reduce the required size of these solar panels, by reducing the power needed by the spacecraft, has the potential to simplify and lower the cost of access to these outer planet destinations.

In this paper, we describe how cold-propulsion technology, in coordinated developments across NASA centers, can reduce the power needs of future Planetary Science spacecraft by approximately $1 / 3$. This technology, with the appropriate investments by NASA, is on a path towards infusion into various NASA planetary science missions that can launch well within the 2020's decade.

\section{The Power Budget of an Outer-Planet Mission is Driven by the Heat Radiatively Lost to Space}

For a typical solar-powered spacecraft, the power needs are met by direct generation to handle near-constant loads plus battery stored power to manage temporary demand peaks. To a firstorder, the near-constant load generally sizes the solar panel array and the transient load generally sizes the battery. While the power budget has many customers (e.g., payload electronics, telecommunication, thermal, GNC, propulsion, etc.), the major contributor to the near-constant demand - and thus to the solar array size required - is the power necessary to balance the heat radiated to space. For example, the highest total power demand for the Europa Clipper mission during a Jupiter Tour occurs during the preparation for and execution of the Jupiter Orbit Insertion (JOI) maneuver, and amounts to about 630 Watts nominally. Roughly $60 \%$ of this load accounts for the heat lost to space. At other scenarios during the Tour this fraction increases to approximately $70 \%$.

This heat loss to space is of course determined by the temperature the spacecraft core must be maintained at, the surface area of the Multi-layer Insulation (MLI), and the MLI emissivity. Since the MLI emissivity is anchored to the State-of-the-Art (SoA) minimum value of 0.03, it can be seen that this heat loss is largely propulsion subsystem-driven, as propellants determine both the minimum temperature required to preclude freezing, and the tank sizes which comprise the bulk of the spacecraft core envelope covered by MLI. In the case of the Europa Clipper spacecraft, for example, the minimum Allowable Flight Temperature (min AFT) is $0^{\circ} \mathrm{C}$, to allow adequate margin over the maximum freezing point propellant - MON-3 oxidizer in this case - 
of about $-15^{\circ} \mathrm{C}$. The high density of the $\mathrm{MMH} / \mathrm{MON}-3$ propellant combination chosen results in an MLI-wrapped spacecraft core cylinder of roughly 5 feet in diameter by 16 feet length.

\section{Cold Propellants Offer an Optimum Solution to Power-Starved, Cost-Challenged Missions}

With respect to their freezing point, the available liquid chemical propellants may be grouped into the three classes shown in Table 1.

Table 1. In-Space Liquid Chemical Propellants Available*

\begin{tabular}{|c|c|c|c|c|c|c|c|}
\hline \multirow[b]{3}{*}{ Propellants } & \multicolumn{3}{|c|}{ Earth-Storable (SoA) } & \multicolumn{2}{|c|}{ Cold-Prop } & \multirow{2}{*}{\multicolumn{2}{|c|}{$\begin{array}{c}\text { Cryogenic } \\
\text { Bi-Propellant }\end{array}$}} \\
\hline & \multirow{2}{*}{$\begin{array}{c}\text { Mono- } \\
\text { Propellant } \\
\text { HPH }\end{array}$} & \multirow{2}{*}{$\begin{array}{c}\text { Dual-Mode } \\
\text { HPH/ } \\
\text { MON-3 }\end{array}$} & \multirow{2}{*}{$\begin{array}{c}\mathrm{Bi}- \\
\text { Propellant } \\
\mathrm{MMH} / \\
\mathrm{MON}-3\end{array}$} & \multirow{2}{*}{$\begin{array}{c}\text { Mono- } \\
\text { Propellant } \\
\text { HPB }\end{array}$} & \multirow{2}{*}{$\begin{array}{c}\text { Bi- } \\
\text { Propellant } \\
\text { MMH/ } \\
\text { MON-25 }\end{array}$} & & \\
\hline & & & & & & LCH4/LO2 & LH2/LO2 \\
\hline $\begin{array}{c}\text { Max. FP } \\
\left({ }^{\circ} \mathrm{C}\right)\end{array}$ & 2 & 2 & -15 & -55 (est.) & -52 & $\begin{array}{c}-183 \\
(\mathrm{LCH} 4) \\
-219(\mathrm{LO} 2)\end{array}$ & $\begin{array}{l}-259 \text { (LH2) } \\
-219(\mathrm{LO} 2)\end{array}$ \\
\hline $\begin{array}{l}\text { Min. AFT } \\
\left({ }^{\circ} \mathrm{C}\right)\end{array}$ & 10 & 10 & 0 & -40 (est.) & -40 & $\begin{array}{c}-170 \\
(\mathrm{LCH} 4) \\
-200(\mathrm{LO} 2)\end{array}$ & $\begin{array}{l}-255(\mathrm{LH} 2) \\
-200(\mathrm{LO} 2)\end{array}$ \\
\hline TRL & 9 & 9 & 9 & 2 & $4-5$ & 3 & 3 \\
\hline \multicolumn{8}{|c|}{$\begin{array}{l}* \mathrm{HPH}=\text { High-Purity Hydrazine. MON-X = Mixed Oxides of Nitrogen with X\% Nitric Oxide (NO) content in } \\
\text { dinitrogen tetroxide/nitrogen dioxide (N2O4/NO2) equilibrium mixtures. MMH = Monomethylhydrazine. HPB = } \\
\text { Hydrazine Propellant Blend. LCH4 = Liquid Methane. LO2 = Liquid Oxygen. LH2 = Liquid Hydrogen. FP = Freezing } \\
\text { Point. AFT = Allowable Flight Temperature. Note: “Green” propellants (e.g., AF-M315E, LMP-103S, MXP-351) } \\
\text { have been omitted for simplicity since they offer no advantage with respect to their freezing points. }\end{array}$} \\
\hline
\end{tabular}

Earth-storable propellants are utilized by the overwhelming number of spacecraft today, and constitute the SoA. Even predominantly electric-propulsion spacecraft, such as Dawn, typically use Earth-storable propellants for high-thrust maneuvers. These flight-proven propellants, however, have relatively high freezing points. Monopropellant and dual-mode systems, such as used on the Mars 2020 and Juno spacecraft, respectively, are limited by their hydrazine fuel to a min AFT of $10^{\circ} \mathrm{C}$. Bipropellant Earth-storable systems are limited by the MON-3 oxidizer to a min AFT of $0^{\circ} \mathrm{C}$. This $10^{\circ} \mathrm{C}$ difference alone reduces the heat loss to space by $15 \%$, and consequently the solar array size by about $8 \%$, which is the reason the Europa Clipper project switched from the $\mathrm{HPH} / \mathrm{MON}-3$ to the $\mathrm{MMH} / \mathrm{MON}-3$ propellant combination during Phase $A$.

Cold-prop candidates are derivatives of their Earth-storable versions. Given their different Technology Readiness Levels (TRL), it is best to describe the bipropellant and the monopropellant options separately.

With a min AFT of $-40^{\circ} \mathrm{C}$, cold propellants have the potential to cut the heat lost to space to about half over the SoA. Thus, for a spacecraft whose power demand is $2 / 3$ radiative heat loss, cold-prop would reduce the required solar panel surface area by roughly $1 / 3$. This order-ofmagnitude benefit assessment was validated in a JPL Team-X Study of the Enceladus Life Finder 


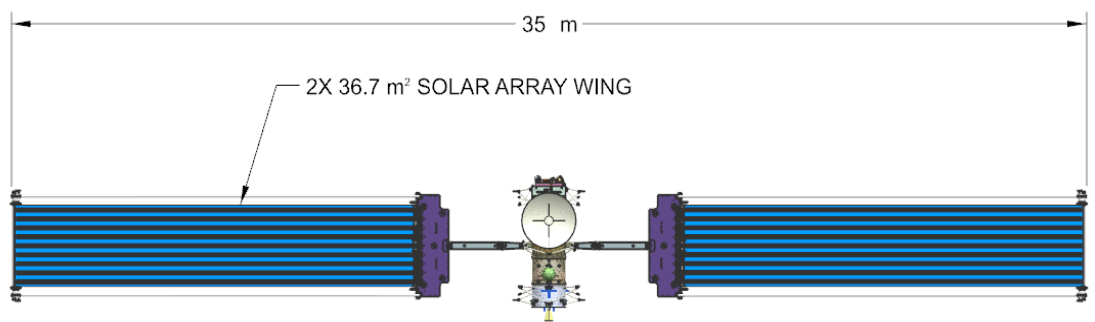

Cold-Prop ELF

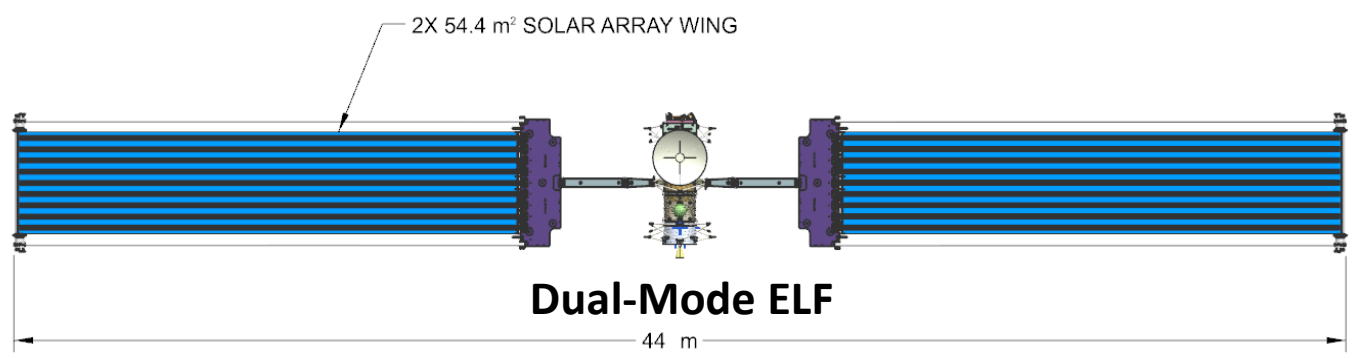

\begin{tabular}{|c|c|c|c|c|}
\hline Subsystem & Power Impact & Mass Impact & Cost Impact & Notes \\
\hline Propulsion & $\begin{array}{l}-43 W \text { (no CatBed or } \\
\text { valve heaters) }\end{array}$ & $\begin{array}{l}-15 \text { kg (dry) } \\
-130 \text { kg (prop) }\end{array}$ & $+\$ 7.7 \mathrm{M}$ (net) & $\begin{array}{l}\text { Assumed }+\$ 10 \mathrm{M} \text { for one } \\
\mathrm{MMH} / \mathrm{MON}-25 \text { engine dev }\end{array}$ \\
\hline Thermal & $\begin{array}{l}-52 W \text { (Safe Mode, no } \\
\text { make-up heaters) }\end{array}$ & No Change & No Change & $\begin{array}{l}\text { Active s/s assumed though } \\
\text { passive appeared feasible }\end{array}$ \\
\hline Power & $\begin{array}{l}-95 \mathrm{~W} \text { (out of } 325 \mathrm{~W} E O L \\
\text { margined) }\end{array}$ & $\begin{array}{c}-65 \mathrm{~kg}\left(36 \mathrm{~m}^{2}\right. \\
\text { smaller } \mathrm{SA})\end{array}$ & $-\$ 10.1 \mathrm{M}$ & $\begin{array}{l}\text { SA area reduction to } 73 \mathrm{~m}^{2} \\
\text { from } 109 \mathrm{~m}^{2}\end{array}$ \\
\hline Mechanical & No Change & $-3 \mathrm{~kg}$ & $-\$ 1.1 \mathrm{M}$ & Per same model basis \\
\hline Other & No Change & $-2 \mathrm{~kg}$ & $+\$ 0.7 \mathrm{M}$ & Mostly model changes \\
\hline Total & -95W SA sizing case & $-215 \mathrm{~kg}$ Launch & $-\$ 2.8 \mathrm{M}$ & Project A-D Cost Delta \\
\hline
\end{tabular}

Figure 1. Impact of Cold-Prop over Dual-Mode Systems in the ELF Mission

(ELF) mission that compared the dual-mode and the cold-prop bipropellant systems. Figure 1 summarizes the results. Not only was the anticipated $1 / 3$ reduction in power budget and solar array size confirmed, but a $215-\mathrm{kg}$ launch mass reduction and net project cost decrease accounting for the cold-prop technology development program - were also predicted. The $\mathrm{MMH} / \mathrm{MON}-25$ cold-prop combination shares all the material compatibility and flight hardware heritage of the SoA MMH/MON-3 set, with the exception of the thrusters. MON-25 differs from MON-3 in the fraction of nitric oxide (NO) content; $25 \%$ versus $3 \%$. The main physical property difference is the higher vapor pressure of $\mathrm{MON}-25$ (at the same temperature), which needs to be accounted for in design, but presents no unusual traits otherwise. The $-40^{\circ} \mathrm{C}$ min AFT also matches the cold operational capability of most other currently available spacecraft hardware, including the battery and electronics, so implementation is near "plug-and-play", as it requires no significant component technology advances beyond the thrusters. The minimum operational temperature capability of any given instrument payload would have to be assessed on a caseby-case basis, of course. 
The cold-prop monopropellant option shown in Table 1 is an Aerojet-Rocketdyne (AR) proprietary hydrazine blend designed to suppress the conventional hydrazine vapor pressure. With an estimated freezing point of $-55^{\circ} \mathrm{C}$ it also has the potential to drastically reduce spacecraft power requirements. The state of development of both cold-prop options is discussed below.

It is helpful to parse the cryogenic options by in-space operation viability. The LH2/LO2 option is not considered desirable or viable for in-space propulsion for these reasons: (a) It offers no net mass or cost advantage over existing alternatives, at least for robotic long-duration missions such as envisioned for planetary science. The extremely low density of liquid hydrogen mandates very large and heavy fuel tanks which, coupled with the required Cryogenic Fluid Management (CFM) hardware mass, more than offsets any mass advantage offered by the cold temperature operation and the higher specific-impulse performance. (b) The required thermal subsystem is prohibitive. $\mathrm{LH} 2 / \mathrm{LO} 2$ would require at least three thermal-control zones within the spacecraft: $-256 \pm 3^{\circ} \mathrm{C}$ for the Zero Boil-Off (ZBO) fuel tank, $-201 \pm 18^{\circ} \mathrm{C}$ for the ZBO oxygen tank, and $>-50^{\circ} \mathrm{C}$ for the rest of the spacecraft core. For these reasons liquid hydrogen-based propulsion systems are best suited to first- and second-stage launch systems, where the relatively brief durations enable reasonable boiloff management. Methane/oxygen engines could deliver higher specific impulse than their SoA bipropellant counterparts, but their systems have larger dry mass owing to their lower-density and the CFM hardware required. The LCH4/LO2 cryogenic option is probably viable, but the net advantage for a robotic mission is limited to very large delta- $\mathrm{V}(>3,000 \mathrm{~m} / \mathrm{s})$ missions due to the higher dry mass. For these missions, however, now flight-proven electric propulsion systems out-perform cryogens. The Dawn mission, for example, delivered over $11,500 \mathrm{~m} / \mathrm{s}$ delta- $\mathrm{V}$. The best future application for LCH4/LO2 propulsion is probably human exploration missions, given the additional life-support and In-Situ Resource Utilization (ISRU) functionality of these propellants.

It should be noted that the benefits of a cold-prop architecture are maximized for missions that use solar power and require substantial chemical propulsion relative to the spacecraft mass, such as Cassini, Juno, Europa Clipper, and ELF. Missions utilizing nuclear power typically still need some chemical propulsion, but the heat associated with avoiding propellant freezing can be readily reaped from the waste heat of the Radioisotope Thermoelectric Generator (RTG) with passive or active thermal subsystems. Similarly, solar-powered missions where the main delta-V is supplied by electric propulsion by definition already carry substantial power generation capability and have only modest amounts of liquid propellant on board. In such cases the energy savings associated with lower freezing point propellants are a small fraction of the power available. 


\section{Substantial Progress Enables the Next Steps}

Given the anticipated advantages of implementing chemical propulsion subsystems that operate at lower freezing points, several investigators have performed testing on some of the thrusters required. The most recent and currently active project is the MSFC Thruster Advancement for Low-temperature Operation in Space (TALOS) Program, which is currently working with Frontier Aerospace Corporation (FAC) to develop a pair of thrusters, at 150-lbf and 10-lbf thrust levels, for the Astrobotic Moon lander Peregrine. This application entails warmer propellants $\left(-20^{\circ} \mathrm{C}\right.$ vs. $\left.-40^{\circ} \mathrm{C}\right)$ and different operational modes than are required for an outer-planet exploration spacecraft (relatively brief pulses vs. extended-duration burns). Thus, JPL has partnered with MSFC and FAC to extend the design capability of these thrusters for deep-space exploration. As of this writing the state of maturity of the 150-lbf engine is estimated at TRL 5 and of the 10-lbf engine at TRL 4. Critical testing is planned in the near future which could alter this assessment, however.

It should be noted that the TALOS technology development effort was preceded by several unsuccessful attempts. Around 2015 a MSFC-AR effort to develop a 100-Ibf In-Space Engine (ISE-100) was ended after combustion stability issues were encountered, even as subsequent AR R\&D development achieved a TRL of about 4. In 2018 a JPL-Moog team performed cold-prop hot-fire testing of a 6-lbf thruster that was previously flight-qualified for $\mathrm{MMH} / \mathrm{MON}-3$ service and failed to achieve the targeted performance and thermal stability. These efforts fell short in spite of earlier successes that demonstrated the concept viability. Around the turn of the century there were concerted efforts by the JPL Mars Ascent Propulsion System (MAPS) and the GRC Mars Flyer Programs, for example, to assess the feasibility and potential risks of the $\mathrm{MMH} / \mathrm{MON}-25$ propellant combination operating at $-40^{\circ} \mathrm{C}$. These two projects employed thrusters developed for $\mathrm{MMH} / \mathrm{MON}-3$ and tested them with $\mathrm{MMH} / \mathrm{MON}-25$. These hot-fire tests successfully demonstrated acceptable and predictable combustion and thermal performance in Kaiser Marquardt (now part of AR) 5-lbf and AMPAC (now part of Moog) 2-lbf thrusters.

While the current MSFC-JPL TALOS-enabled partnership broadly encompasses the two main bipropellant propulsion applications for landers and orbital missions, it should be noted that the continuous-burn, deep-throttling mode of landing (as opposed to pulsing), such as in the Apollo and Surveyor missions, has not yet been addressed in any cold-prop development effort to date. Deep-throttling cold-prop engines are highly desirable for larger payloads and longer duty cycles. Future Mars 2020-class landers, such as the Mars Sample Return (MSR) Sample Retrieval Lander (SRL), could reap drastic mass benefits by the use of cold-prop. Not only would the associated spacecraft require much less power, but the higher-performing bipropellant would break the current approximately 1,500-kg payload ceiling achievable with the SoA monopropellant landing system.

As far as the cold-prop monopropellant HPB, it is a much more recent technology, and therefore is not as advanced. Like the cold-prop bipropellant MMH/MON-25, the HPB can be used with existing monopropellant flight hardware with some modifications to the thruster 
only. These changes do not involve higher catalyst bed preheat temperature than $\mathrm{HPH}$, or higher-temperature materials, nor does it yield any less specific impulse performance. The extent of development to date includes safety verification (i.e., low impact and electrostatic shock sensitivity and high thermal stability), and preliminary hot-fire demonstration in a standard flight production $\mathbf{S 4 0 5}$ hydrazine thruster catalyst, which showed normal pulse repeatability and roughness. Some of the fundamental issues that need to be addressed in a subsequent TRL 3 development program are

- Ignition and decomposition stability at $-40^{\circ} \mathrm{C}$. The hot-fire testing performed to date has been with room-temperature HPB only.

- Flow behavior near the freezing point. The HPB thickens significantly below $-25^{\circ} \mathrm{C}$ and the fluid rheology needs to be characterized.

Once these basic performance metrics are validated, further development of cold-prop monopropellant thrusters would follow a conventional path: verify performance in flightrepresentative thruster, characterize bed-loading performance sensitivity, characterize HPB engineering properties, establish material compatibility via testing, and obtain Department of Transportation (DOT) certification.

\section{$\underline{\text { Remaining Steps to Flight Infusion }}$}

In order to enhance the affordability of a broad range of future planetary science missions, the following three-pronged cold-prop general implementation roadmap is suggested.

1. We recommend continued investment in the MSFC-led TALOS program as a matter of high priority. The Astrobotic lander Peregrine is the earliest opportunity for flight infusion, and the associated development promises to resolve ancillary but important technical implementation items beyond the engines' development. The Peregrine lander is scheduled for launch in late 2021. As stated, however, a successful TALOS program will infuse technology consistent with a relatively small lander that demonstrates only a fraction of the cold-prop benefit potential (i.e., pulsing thrusters at $-20^{\circ} \mathrm{C}$ min AFT).

2. Therefore, we also recommend as high priority the enhanced funding support for the JPLled effort to extend the TALOS engines' technology for outer-planet missions (i.e., long burns and $-40^{\circ} \mathrm{C}$ min AFT). In practice, this means that further development of the lander and of the orbiter outer-planet engine versions will likely diverge at the Design Verification \& Test (DVT) phase. Pending a successful outcome of the ongoing workhorse test phase, the outer-planet engines could begin the DVT phase as early as the summer of 2021. Flight qualification to a specific mission could be completed by late 2022, and support a spacecraft launch three years hence, at the earliest.

3. Lastly, we recommend funding of a 2,000-lbf thrust deep-throttling $\mathrm{MMH} / \mathrm{MON}-25$ engine development program. Assuming a 2021 start, we estimate this technology could support a 2027 launch date at the earliest.

As far as the cold-prop monopropellant HPB, it is recommended that development funding be secured to proceed through at least TRL 3 to access technical feasibility. 


\section{Summary}

Most future planetary exploration missions will be power-starved and cost-challenged. Coldpropulsion provides a means for reducing the power requirement of a typical outer-planet solar-powered spacecraft by approximately $1 / 3$, and reap hundreds of kilograms of mass savings, as well as reduced costs, as compared to the SoA propellant options available.

The proposed MMH/MON-25 bipropellant and HPB monopropellant thrusters can be "plugged in" to existing flight hardware and provide essentially the same performance. Cold propellants operating at $50^{\circ} \mathrm{C}$ lower temperatures compared to conventional alternatives enable the spacecraft-level benefits outlined above.

The current collaboration effort between MSFC and JPL for development of MMH/MON-25 cold-prop flight engines has proven to be very fruitful, and should be considered a high priority to enhance the chances of a successful lunar lander as well as an outer-planet mission infusion. Similarly, the HPB cold-prop monopropellant thruster technology development should be considered a priority for funding through at least TRL 3 to assess viability of the concept, which also has high payoff potential. 